\title{
Analytical Quality by Design with the Lifecycle Approach: A Modern Epitome for Analytical Method Development
}

\author{
Maher Abdulrazzaq Alhakeem", Mihaela Violeta Ghica², Cristina Dinu Pîrvu², Valentina Anuța², \\ Lăcrămioara Popa² \\ 1. University of Medicine and Pharmacy "Carol Davila", Bucharest, Romania \\ 2. Department of Physical and Colloidal Chemistry, Faculty of Pharmacy, University of Medicine and Pharmacy "Carol Davila", Bucharest, Romania
}

Quality by Design is the methodical method to development concept that starts with the predefined objects. The method put emphasis on the process of development of a product, the control process, which is built on risk management and comprehensive knowledge of science. The concept of QbD applied to analytical method development is known now as AQbD (Analytical Quality by Design). Comprehension of the Analytical Target Profile (ATP) and the risk assessment for the variables that can have an impact on the productivity of the developed analytical method can be the main principles of the AQbD. Inside the method operable design region (MODR), the AQbD permits the movements of the analytical methods. This paper has been produced to discuss various views of analytical scientists, the comparison with conventional methods, and the phases of the analytical techniques.

Keywords: analytical quality by design, lifecycle approach, method operable design region

Received 4 February 2019 / Accepted 23 May 2019

\section{Introduction}

International Conference on Harmonization (ICH) Q8 (R1) guideline defines Quality by Design (QbD) as "a systematic approach to development that begins with predefined objectives and emphasizes product and process understanding and process control, based on sound science and quality risk management" [1]. The approach of QbD has been implemented in the manufacturing of pharmaceutical through numerous enterprises as Process Analytical Technology (PAT) and FDA guidelines. Recently FDA has approved new drug applications based on AQbD and termed it as benefits and importance of $\mathrm{QbD}$ in the analytical technique development cycle for accepting drug excipient interaction. Additionally, for the determination of critical quality attributes during the process, experiment, control, and continuous process verification to monitor the product quality trends; Hence this resonance attracting the pharmaceutical industry to evoke the AQbD [2]

The elementary notion of the QbD process of testing cannot put quality into an object but rather it must be constructed into the product. An essential aspect of $\mathrm{QbD}$ is that it understands how the choice of constraints can have an impact on the development process. The understanding attained during the process development can assist in the formulation of the products limits and the design space best suited for a particular drug.

Similar ideologies of QbD are applied in the development of analytical methods becoming Analytical Quality

* Correspondence to: Maher Abdulrazzaq Alhakeem

E-mail: abdul.maher@drd.umfcd.ro by Design (AQbD). In similarity to the concept of QbD, the results obtained from the $\mathrm{AQbD}$ process are assumed, suitable for the product and consistent in providing the envisioned performance during the lifecycle of the product. Despite a lot of discussion concerning AQbD the quality assurance personnel view $\mathrm{AQbD}$ as the better solution to avoid out of specifications (OOS) and out of trend (OOT) and minimize risk in method failure [3, 4].

The comprehensive knowledge that is gained while using this concept is beneficial in the establishment of the method operable design region, (MODR). This is a multidimensional region that is centered on the process properties which influences the performance of the product [1].

Safety and efficiency should be considered paramount by ensuring that pharmaceutical products are required to be healthy and easily reproduced. The process of creating the pharmaceutical products entails the production of information on the materials such as an intentional addition of an ingredient to a drug component. With the advancement in technology comes the change in both the quality and quantity of the material information that facilitates knowledge development [5].

The process of AQbD is a major stage of the control strategy in the quality system of the pharmaceutical industry. This concept constitutes the constraints and features linked with the drugs and the operating environment and their related processes. Although current Good Manufacturing Process (cGMP) regulation has been in place for a long time, many of the pharmaceutical companies are still experiencing problems in relation to issues of quality control. Quality Control is emphasized in risk management 
during the development of the product. Therefore, due to the dependency of these pharmaceutical companies for development processes to be robust, there is a great need for the AQbD concept [6]. This is an indication of the quality of this concept, and the robustness of the product in its lifecycle.

The lifecycle assessment (LCA) approach is a rooted methodical method. The technique is used in the application of environmental effects, which has been practiced for the products. The purpose of using this approach in the analytical process is the elating the development process to the requirements of the products to develop the method reliability (figure 1) [7].

Following the lack of explanatory reviews, this article aim focuses on different views of experts on the application of AQbD in the pharmaceutical quality system. Additionally, the article links the views with the lifecycle method.

\section{Conventional Approach versus Analytical Quality by Design}

The traditional process in the pharmaceutical industry was Quality by Testing $(\mathrm{QbT})$. However, this becoming outdated; in the QbD philosophy there is assurance of the quality of the product, and hence it is more favored [8]. Currently, the pharmaceutical industry is using the QbD method to reduce the cost and time and assurance of the quality of the products [9]. The impacts of this process in the pharmaceutical industry have been expanded after the initialization of the FDA guidelines. The different methods in use include FDA cGMP, the process analytical technology. The target of the quality process is to ensure that the product is safe for use by the patients. The AQbD checks the Out-of-Trend (OOT), Out-of-Control (OOC) and Out-of-Specification (OOS) results [10]. This proves that the traditional process does not provide assurance of the product's safety. Hence the pharmaceutical industry can make huge improvements in the components of the product [11].

\section{Application of Analytical Quality by Design (AQbD) ad- vantages, expectations, and obstacles}

According to pharmaceutical quality systems, analytical techniques are the primary part of the control strategy. Therefore, the implementation of $\mathrm{QbD}$ in manufacturing as a control mechanism will ensure predetermined performance and the quality of the product [3]. This comprises attributes and parameters related to drug product and drug substances components including instrument operating conditions, facility, finished product specification, and the related analytical methods [12].

The adoption of $\mathrm{AQbD}$ is expected to enhance the concept of right analytics at the right time which has an essential role in drug product development cycle [13].

The advantages of AQbD concept in product development [14] can be pointed out: the advancement of a method that is robust; the concept is applicable in the lifespan of a product; the regulations are flexible; the movement of a product inside the design area is not seen as a variation in developments; the concept allows for constant progress during the development process; the concept evades revalidation of the product.

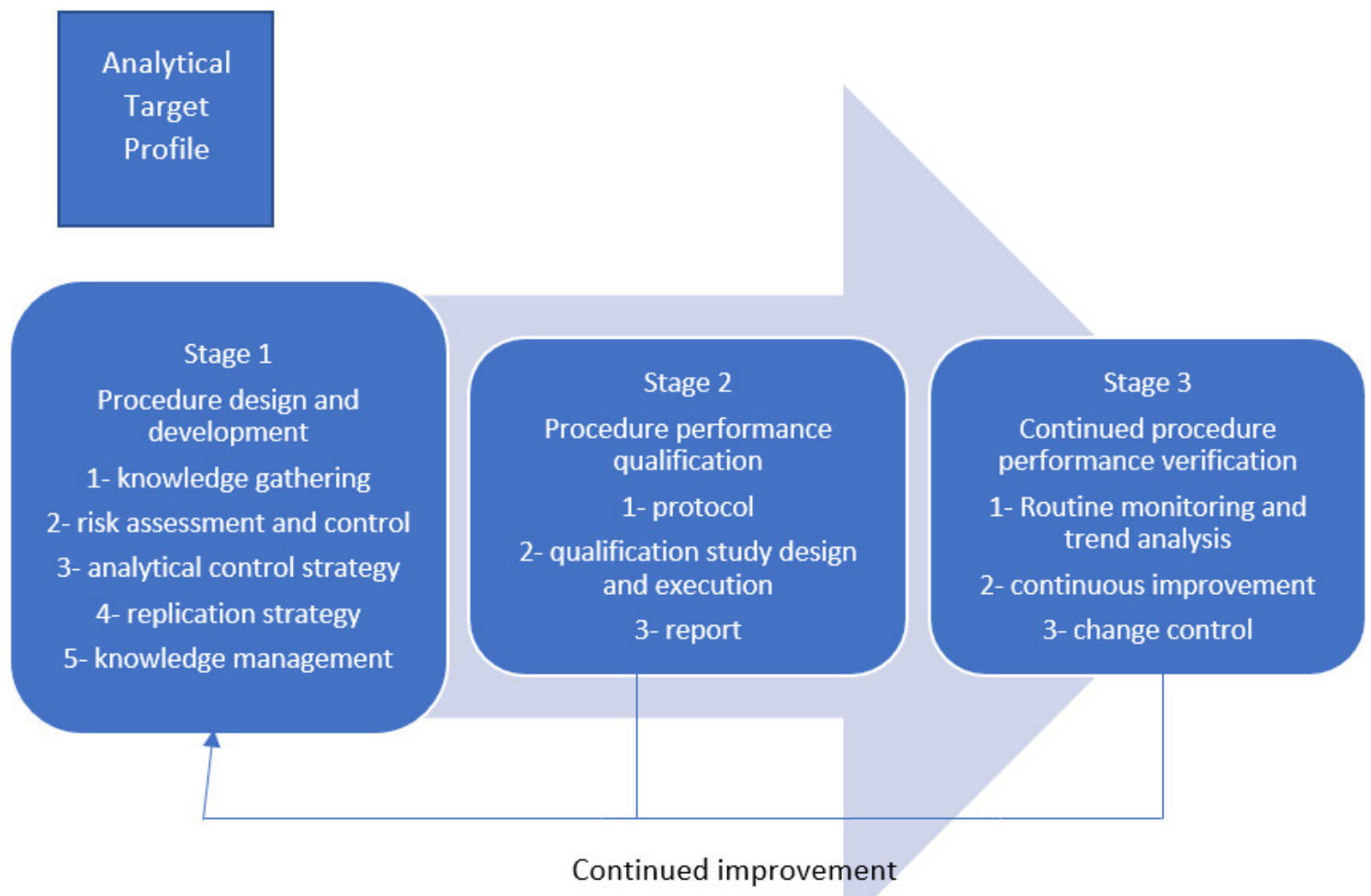

Fig. 1. The analytical procedure lifecycle [7].๑ copyright 2017 U.S. Pharmacopeial convention (USP). 
Obstacles that hinder the application of the analytical quality by design are mainly that there is no full comprehension of this concept in the pharmaceutical industry and the absence of a clear description of the AQbD elements.

The USP Stimuli articles establish that the analytical method lifecycle comprises of three phases:

- Phase 1. The method design: the depiction of the demands and the nature of the process;

- Phase 2. The validation method: guarantee that the process meets the design;

- Phase 3. The life cycle management/Continued procedure performance verification confirms that the process remains in the controlled state [15].

\section{Method design}

Method design from point of view of AQbD incorporates the Method Operable Design Region (MODR), that means defining Analytical Target Profile (ATP), the experimental design screening and establishing Critical Quality Attributes (CQA).

\subsection{ATP (Analytical Target Profile)}

The analytical target profile is the necessary tool for product development, as it is outlined in the ICH Q8 guidelines. ATP describes the essential requirements to be measured which influence product advancement. The ATP is a collection of all the presentation constraints that are required for the planned analytical application [16]. An ATP is advanced for every attribute which is present in the control strategy. Analytical Target Profile defines the goal of the analytical technique development process and relating the outcomes of the method to achieve QTPP. Based on EFPIA and PhRMA ATP can be defined as a statement that defines the purpose of the method which is utilized to drive method design, selection, and development activities [3].

Analytical Target Profile is a crucial parameter in AQbD facilitating the greater constant improvement of analytical techniques and their choice when the ATP statement is approved by the regulatory authorities. Internal change control management in the pharmaceutical industry is responsible for perfect implementation of ATP to offer regulatory flexibility $[12,17]$.

The general ATP of the analytical procedures comprises of [18]: selecting the target of analytic process (Active Product Ingredient API and impurities); selecting the techniques to be used in process (HPLC, GC, HPTLC, Ion Chromatography, chiral HPLC, ...); choosing the required method (assay or impurity profile or residual solvents).

The selected method should be precise and accurate; these are essentially the characteristics and provide vital information for the purpose of computing an unknown amount of the material for use in the process method. In the absence of accuracy and precision, a method will not be correct. In order to achieve a method which is accurate and precise, some important characteristics need to be evaluated [19]. These characteristics could be an acceptable specification, a space that is stated linearly, adequate peak determination, or else. These characteristics ensure that widespread data set for setting the constraints of the method.

\subsection{Critical Quality Attributes (CQA)}

The ICH Q8 guidelines describe CQA as the chemical, microbiological, physical and biological properties of a drug. These properties should be within the constraints to guarantee that the end product is of desirable quality [20]. In the instances of process related to CQA the drug products quality characteristics for example dissolution, assay, chromatographic purity, residual solvents, microbial limits, dosage unit's uniformity, water content, suspensions, viscosity in creams, the medicament in soft gelatin capsules, and medicament are regarded as vital quality properties. While in case of $\mathrm{AQbD}$ considering an HPLC technique development as typical example theoretical plate count, tailing of the peak, the resolution between impurities and main analyte, capacity factor, peak purity are considered as CQA [14].

As features of the CQA, the accuracy and correctness of the development process are to be calculated holistically, for the identification of the Target Measurement Uncertainty (TMU). This TMU is connected to the result of the development process $[21,22]$. The TMU is not a measurement that can be attained on its own; rather it is the maximum measurement that can be accepted by the Measurement Uncertainty (MU) [23].

\subsection{Risk management}

Risk management is defined as the systematic analytical method for the examination, regulation and, acknowledgment and validation of the threats to the quality of the finished product [24]. It is carried out throughout the lifespan of the product, which in this case is a drug product.

\subsubsection{Risk assessment}

Risk assessment is an essential phase of the risk management process. This phase improves the quality of the process. It can be defined as a single or combined view of the occurrence of any impairment or the degree of the impairment to the process. Risk assessment assists in increasing the quality of the development process. In addition, it is a factor for the impact of the initial variables on the analytic development process. Through the process of risk assessment, the perilous attributes that can disturb the quality of the end product are documented.

The important reasons for risk assessment are to identify the degree of dangers at the start of the analytic development of drug; to decrease the variety of CQA chosen; to acknowledge the suitable requirements, the constraints, and production regulations [15].

The known methods for risk assessment are fault tree analysis; failure mode effect analysis; risk ranking and fil- 
tering; Failure modes and effects analysis (FMEA); Structured "What-if" Technique (SWIFT), the fishbone diagram [25].

There are some questions [26] in the risk assessment process as:

- What mistake can take place?

- What is the possibility of this happening?

- What are the difficulties?

In the risk assessment process, the most essential notion in the compliance phase is the concept of the decision rules. These guidelines can be defined as the acceptance or rejection of the product; this is in harmony with the measured values of the product. The constraints and uncertainty are considered in setting the acceptance limits of the possibility of making a mistake during the analytic development process. While using the established constraints, two areas are considered the acceptance and rejection areas. The product is then subjected to the tests if the product lies in the rejection area, it is considered as compliant, or otherwise, the product is declared defective [27].

\subsubsection{Risk control phase}

It is essential to decrease the dangers to a satisfactory level; risk control is divided into two categories. These categories are risk reduction and risk approval.

In risk reduction, there are two steps: remedial activities in order to solve the inconsistency and remedial activities to ensure the inconsistency are not repeated [28].

In risk acceptance, the steps are the assumptions of dimensions to be considered; the conclusions on the nature of the measurements; defining the following actions to be applied; managing the review of the process; risk statement, the administration can decide on the steps to be taken. The Sturdiness of the product should be examined in all the lifecycle of the product. This feature is vital in the process of selecting the best plan for authorization. The analytical processes developed at the initial stage are determined by the assortment of an inclusive procedure and the corresponding information of the product (Figure 2).

\subsection{Design of experiments (DoE) in AQbD concept}

The robustness of the product should be examined in all the lifecycle of the product. This feature is vital in the process of selecting the best plan for authorization. The analytical processes developed at the initial stage are determined by the assortment of an inclusive procedure and the corresponding information of the product [29].

The design space attributes and $\mathrm{AQbD}$ are applied to the analytical development process to intensify the suppleness of the process and reduce the dangers that can affect this process. Design of Experiments (DoE), is a credible method used to create the link between the raw products and the end products of the process. Normally the DoE is applied in the $(\mathrm{QbD})$ process by defining the limits of the measurements and attributes in the development process. Experts can apply the DoE to find the operating ranges of the process [30]. Reducing the number of experiments, for example, is essential as it prevents time and money wastage in the development process. Saving time as well money is only attainable through the assessment of the potential risks while ranking them by considering the extent of their severity essential in owing to the number of prior arguments [31].

When applied correctly the DoE can provide a big improvement in precision and robustness subsequently reduce the errors realized in the development process [32]. The DoE method for validation aims at validating the method for a wide variety of concentration; this ensures that any changes in concentration within limits of design space will not need extra validation, because the changes are in the characterized area [21]. Lately, more attention has been put on the DoE applied to the analytical development process.

The DoE has three main applications: the process advancement for new processes or existing ones that need upgrading; analytical process verification; measuring the impact of the analytic methods on the products $[33,34]$.

\subsection{Method control strategy}

The process of creating a control strategy is essential in ensuring that the process is performed as planned on the foundation of the ATP objectives. A process control strategy is a prearranged set of constraints that is aimed at reducing the inconsistency of the process. This method is reliant on the statistics of the whole process. The data which is created during the development and verification process is the foundation of the control strategy. The attributes that are found to have risks have to be managed. The attributes that are high risk are given additional consideration. The control strategy is defined for the attributes which have low risks and can be accomplished. This control strategy is defined and entails the suitable process appropriateness check and verification consistently. Doing this ensures that the process supplies a product with the desired attributes.

\subsubsection{Process analytical technology (PAT)}

PAT is a scheme for assessing, planning and regulating the quantities of the analytical process; it is done constantly in the lifecycle of a product. PAT ensures that the features and quality of the product will be as planned [35]. In the ICH Q8 guidelines PAT is described as a method that assures product remains in the established design space. In a method which is more vigorous, PAT will ensure that active regulation of the attributes and the appropriate alterations of the limits in the setting of initial materials which would otherwise affect the quality of drug are detected [36].

\subsubsection{Knowledge management}

This is the notion of gathering, treating and checking the data from all the previous phases. This ensures that the control strategy is accurate. 


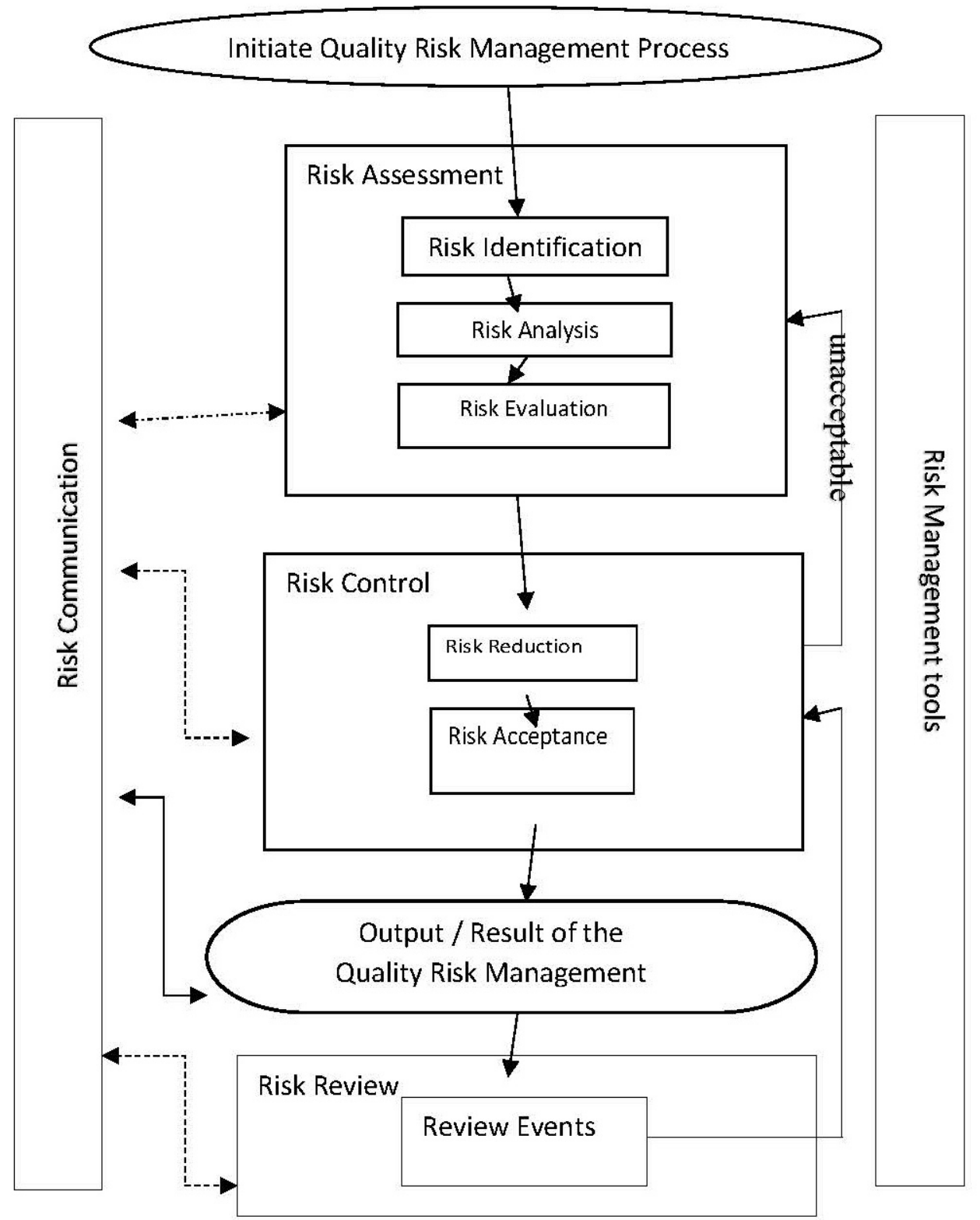

Fig. 2. An overview of risk quality management [24]. () copyright 2005 International Conference on Harmonisation (ICH) guidelines Q9.

\subsubsection{Analytical control strategy (ACS)}

The ATP's primary focus is the identification of the potential risks arising from making incorrect decisions. Contrary to the problem of making improper decisions, decision rules that govern the process of decision-making may not be essential all the time. First, the company should link the acceptable level of risk to the safety of patients. Therefore, the Target Measurement Uncertainty (TMU) aims at maximizing the acceptable uncertainty to meet the ATP hence ensuring an accomplishment of the fitness-forpurpose necessary for the process of analysis. ACS, on the other hand, plays an essential role in providing consistency of TMU during the whole process of analytical procedure (Figure 3).

\section{Method validation}

Method validation entails clarifying that the chosen method will provide information that meets the guidelines of the ATP, in the predicted conditions. Subsequently, the attribute presentation requirements must be put in place before the predicted presentation of the analytical development process. The analytical techniques used in the process of presentation of the prerequisite study should be recognized from the information that is accessible. Method validation can also be understood as the process of verifying and recording of any evidence, method, and apparatus which should be installed correctly. This would, in turn, ensure that the process leads to the results which had been predicted [39].

\section{Continued procedure performance verification / Lifecycle Management}

The last phase of the AQbD process, this phase involves linking the critical quality attributes, the analytical target profile, the MODR, and risk assessment of the process with preceding information considerations. The lifecycle 


\section{Analytical Target Profile (ATP)}

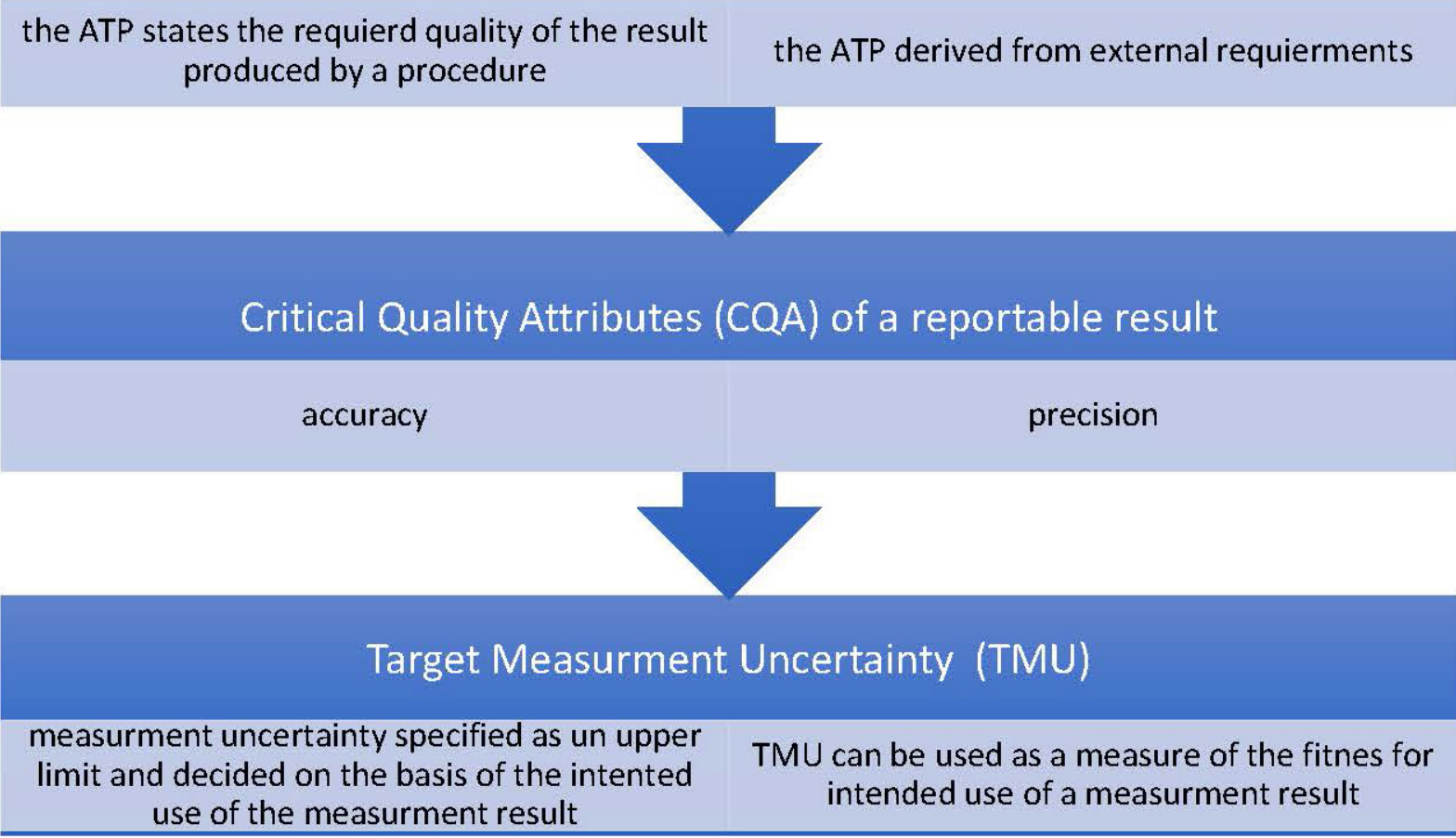

Fig. 3. An illustration of how ATP, CQA, and the TMU relate to one another [9]. ๑) copyright 2016 U.S. Pharmacopeial convention (USP).

management of the process offers the background for describing the method of development of the analytical process, ensuring that it meets planned standards throughout the life of the product [8]. The lifecycle method is determined by the methods which satisfy the constraints, suitable risk assessment is done to reduce the chances of the product failing to meet the standards.

The following stages can advance the analytical development of the product lifecycle [40] advancement of the measuring; advancement of the decision rule; advancement of the ATP; choosing the analytical process that meets the set guidelines.

The adaptation of the previous concepts and the existing concept are used in the verification of the analytical process to support the consistency of the product that is to be examined. And for the development of the reliability of the analytical method throughout the increasing of the understanding and decreasing of the variability. This is done to ascertain that the analytical process correlates with the planned objectives specified in the analytical process. The lifecycle concept is an addition of the existing advantages of the AQbD concept [24].

\section{Regulatory prospect}

In line with pharmaceutical guidelines, the analytical process plays an important part in the control strategy. The analytical process ensures that the planned performance and quality of the finished product is achieved through the use of the analytical $\mathrm{QbD}$ in the drugs manufacturing process [41]. The execution of AQbD is depended on the no- tion of correct examination on the appropriate time; this adopts a vital role in the drug production process. Hence, analytical $\mathrm{QbD}$ execution in the production process as a control strategy ensures that the product meets the set standards [3]. Currently, the problem relating to the faultiness in the analytical method is becoming more prominent especially concerning the departments responsible for the transfers and quality control, considering the robustness of the whole process. The FDA's letter to the pharmaceutical companies which gives more interest to the reliable analytical techniques has in the recent past given rise in the Quality control. Therefore, the success of the company depends on the Quality by Design (QbD) employed in the analysis of the methods [16].

\section{Conclusions}

Quality by Design (QbD) is a concept extensively used now in the pharmaceutical industry than the traditional process. This method reduces product unpredictability and the connected dangers that can be incurred. The execution of Analytical Quality by Design (AQbD) in the product development is done through understanding the critical quality attributes, risk assessment and determination of the design space. The execution of $\mathrm{QbD}$ to the analytical development process has its advantages. The process provides a systematic approach; with the approach one is likely to explain the rudimentary and misleading concerns. In addition, the Design of experiments (DoE) strategy helps the assessor with more useful and precise data about the analytical process development. Through having a good 
understanding of the ATP and the MODR, one can create an analytical procedure that is suitable for the demands of the ATP.

Consequently, it is important to use the application software of a computer to get more accurate data of the investigation. The AQbD approach to the lifecycle of the analytical method performance focuses on the envisioned purpose of the analytical procedures. This allows for the basic interpretation of the analytical process. Nonetheless, it is the ATP which incorporates the TMU in the analytical development process. The decision rule permits acceptable probabilities to be established, these probabilities are made with the aim that all the dangers can be handled.

\section{Acknowledgments}

This study was financially supported by SAN-CDCP, Contract PFE_23/2018, Romania.

\section{Conflict of interests}

The authors declare no conflicts of interest.

\author{
Abbreviations \\ QbD = Quality by Design \\ $\mathrm{AQbD}=$ Analytical Quality by Design \\ QbT $=$ Quality by Testing \\ MODR=Method Operable Design Region \\ OOS = Out-of-Specification \\ OOT=Out-of-Trend \\ $\mathrm{ICH}=$ International Conference of Harmonization \\ PAT $=$ Process Analytical Technology \\ FDA $=$ Food and Drug Administration \\ cGMP = current Good Manufacturing Process \\ LCA = Life Cycle Assessment \\ TMU = Target Measure Uncertainty \\ QTPP = Quality Target Product Profile \\ ATP $=$ Analytical Target Profile \\ $\mathrm{CQA}=$ Critical Quality Attributes \\ $\mathrm{RA}=$ Risk Assessment \\ DoE $=$ Design of Experiment
}

\section{Authors' contribution}

Maher Abdulrazaaq Alhakeem (Conceptualization; Methodology; Resources; Validation; Visualization; Writing original draft; Writing - review \& editing)

Mihaela Violeta Ghica (Conceptualization; Methodology; Writing - original draft; Writing - review \& editing)

Cristina Dinu Pîrvu (Conceptualization; Methodology; Writing - original draft; Writing - review \& editing) Valentina Anuța (Conceptualization; Methodology; Writing - original draft; Writing- review \& editing)

Lăcrămioara Popa (Conceptualization; Methodology; Resources; Supervision; Validation; Visualization; Writing original draft; Writing - review \& editing)

\section{References}

1. $\mathrm{ICH}$ Expert Working Group. International Conference on Harmonization (ICH), Tripartite guidelines, ICHQ8(R2): Pharmaceutical Development. 2009. London.

2. Zlota, "Practical Approaches to Quality by Design (QbD) for Pharmaceutical Process Research, Development and Manufacturing, "Three-day course presented at ZLOTA Company LLC in conjunction with Scientific Update LLP, http://www.scientificupdate.co.uk/training/scheduledtrainingcourses/details/216-actical\%20Approaches\%20to\%20 Quality\%20 by\%20Design\%20for\%20Pharmaceutical\%20Process\%20R.html'D and Manufacturing.

3. Phil JB, John R, Chris J, Melissa HB, Roman S, Simon B. The development phase of an LC method using QbD principles. Journal of Separation Science.2010; 2: 2-8.

4. Monika LJ, Santosh RT. Implementation of $\mathrm{QbD}$ approach to the analytical method development and validation for the estimation of propafenone hydrochloride in tablet dosage form. Chromatography Research International. 2013; 2013:1-9.

5. Ferreira AP, Gamble JF, Leane MM, Park H, Olusanmi D, Tobyn M. Enhanced Understanding of Pharmaceutical Materials Through Advanced Characterisation and Analysis. AAPS PharmSciTech. 2018;19(8):34623480.

6. Taevernier L, Wynendaele E, D Hondt M, De Spiegeleer B. Analytical quality-by-design approach for sample treatment BSA-containing solutions. Journal of Pharmaceutical Analysis. 2015;5(1):27-32.

7. USP Validation and verification expert panel. Proposed New USP General Chapter: The Analytical Procedure Lifecycle [01220?]. United State Pharmacopeial Convention (USP). Pharmacopeial forum .2017;43 (1).

8. Zhang L, Shirui M. Application of quality by design in the current drug development. Asian Journal of Pharmaceutical Sciences.2017;12:1-8.

9. Pallagi E, Ambrus R, Szabó-Révész P, Csóka I. Adaptation of the quality by design concept in early pharmaceutical development of an intranasal nanosized formulation. Int J Pharm. 2015;491(1-2):384-92.

10. Peraman R, Bhadraya K, Padmanabha RY. Analytical Quality by Design: A Tool for Regulatory Flexibility and Robust Analytics. International Journal of Analytical Chemistry.2015; 2015:1-9.

11. Rohin M, Anurag SR. quality by design: an overview of the basic concepts, quality by design for biopharmaceuticals. John Wiley \& Sons, Inc., Publication. Hoboken, NJ, 2009,1-20.

12. Phil N, Phil JB, Tony B, Greg M, Pauline M. QbD for Better Method Validation and Transfer. http://www.pharmamanufacturing.com/ articles/2010/ 060.html. 2010.

13. George LR, Guilong C, David TF et al. Reversed-phase liquid chromatographic method development in an analytical quality by design framework. Journal of Liquid Chromatography and Related Technologies. 2013; 36(18): 2612-2638.

14. Bhusnure OG, Gandge NV, Gholve SB. Sugave BK, Giram PS. A Review on Application of Quality by Design Concept to Analytical Method Development. ljppr.Human, 2017; Vol. 10 (1): 63-75.

15. USP Validation and verification expert panel. Lifecycle management of analytical procedures: method development, procedure performance qualification, and procedure performance verification. United State Pharmacopeial Convention (USP). Pharmacopeial Forum.2013; 39(5).

16. Vogt FG, Kord AS. Development of quality-by-design analytical methods. J Pharm Sci. 2011; 100:797-812.

17. Lynn DT. OOS, OOT, OOC, and OOSC. Pharmaceutical Technology. 2011; 35(10):46-47.

18. N. V. V. S. S. Raman, Useni RM, Hanimi RB.Analytical Quality by Design Approach to Test Method Development and Validation in Drug Substance Manufacturing. Journal of Chemistry. 2015; 2015:1-8.

19. Mayank N, Panwar KS, Chopra VS, Indu B, Trivedi P. Quality by design: a systematic approach to pharmaceutical development. Der Pharmacia Lettre. 2010; 2:111-3.

20. ICH. Q8 (R2) Pharmaceutical development. 2009. http://www.ich.org/ fileadmin/Public Web Site/ICH Products/Guidelines/Quality/Q8 R1/ Step4/Q8 R2 Guideline.pdf. Accessed 26 April 2013.

21. Bettencourt DS., Bulska E, Godlewska-Żyłkiewicz B, et al. Analytical measurement: measurement uncertainty and statistics, European Commission -Joint Research Centre, Luxembourg, Publications Office of the European Union,2013: 19-85.

22. USP Validation and verification expert panel. Analytical target profile: Structure and Application throughout the analytical lifecycle. United State Pharmacopeial Convention (USP). Pharmacopeial Forum.2016; 42 (5).

23. USP Validation and verification expert panel. Measurement Uncertainty for the Pharmaceutical Industry. Pharmacopeial Forum .2018; 44(1).

24. Quality Risk Management Q9, ICH Harmonised Tripartite Guideline, 
2005.

25. David V, Miroslav K. selected overview of risk assessment techniques, Problemy eksploatacji. 2009:19-32.

26. Balaji J, Murugesh S. Analytical Quality by Design - A Legitimate Paradigm for Pharmaceutical Analytical Method Development and Validation. Mechanics, Materials Science \& Engineering. 2017;9. Doi 10.2412/mmse.96.97.276

27. Varanasi UB, B. D. C. N. Prasad. A Framework for Auditing the Evaluation of Uncertainty for Compliance in Information Systems. Lecture Notes on Software Engineering.2015; 3(1).

28. Deviation Handling and Quality Risk Management, World Health Organization (WHO), A note for guidance for the manufacture of prequalified vaccines for supply to United Nations agencies Geneva, Switzerland, July 2013.

29. U.S. Department of Health and Human Services, Food and Drug Administration Center for Drug Evaluation and Research (CDER), Center for Biologics Evaluation and Research (CBER). Analytical Procedures and Methods Validation for Drugs and Biologics Guidance for Industry.July 2015.

30. Mogal V, Dusane J, Borase P, Thakare P, Kshirsagar S. A review on quality by design, Mogal V. et al. Pharmaceutical and Biological Evaluations 2016; vol. 3 (3): 313-319.

31. Meitz A, Sagmeister P, Langemann T, Herwig C. An Integrated Downstream Process Development Strategy along QbD Principles, Bioengineering 2014; 1, 213-230.

32. Kochling J, Wu W, Hua Y, Guan Q, Castaneda-Merced J. A platform analytical quality by design (AQbD) approach for multiple UHPLC-UV and
UHPLC-MS methods development for protein analysis. J Pharm Biomed Anal. $2016 ; 125: 130-9$.

33. Priyanka PP, Sadikali FS, Machindra JC, Sanjay RC. Quality by design in analytical method development and validation. Journal of Environment and Life Science.2017;2:39-45.

34. M. Deepa, K. Ravindra Reddy, S. V. Satyanarayana. A Review on Quality by Design Approach for Analytical Method Development. Journal of Pharmacy Research 2017;11(4):272-277.

35. U.S. Food and Drug Administration CDER. Guidance for industry: PAT-a framework for innovative pharmaceutical development, manufacturing, and quality assurance. 2004.

36. Yu LX, Amidon G, Khan MA, Hoag SW, Polli J, Raju GK, Woodcock J. Understanding Pharmaceutical Quality by Design. AAPS J.2014;16(4): 771-783.

37. USP Validation and verification expert panel. Analytical Control Strategy. United State Pharmacopeial Convention (USP). Pharmacopeial Forum.2016; 42(5).

38. Quality assurance of pharmaceuticals: a compendium of guidelines and related materials. Vol. 2, Good manufacturing practices and inspection. 2nd ed.

39. Le Blond D., Weitzel J., Burdick R. Analytical Quality by Design Approach to the Development Stage in the Lifecycle of an Analytical Procedure. web' Institute of Validation Technology, IVT Network .2017

40. Karmarkar S, Garber R, Genchanok Y, George S, Yang X, Hammond R. Quality by design ( $\mathrm{QbD}$ ) based development of a stability indicating HPLC method for drug and impurities. J Chromatogr. Sci.2011;49(6):439-46. 